\title{
Uses of Raw Products Obtained from Hemp: Fiber, Seed, and Cannabinoids ${ }^{1}$
}

\author{
Navdeep Kaur, Lakesh K. Sharma, Christine Kelly-Begazo, Mark Tancig, and Zachary Brym²
}

This publication is an educational resource on hemp for general audiences in the Hemp 101 series with the purpose of providing knowledge about the uses of hemp for fiber, seed, and cannabinoids.

\section{Introduction}

Hemp (Cannabis sativa L.) is an annual herbaceous plant, native to Asia and now found worldwide (Bouloc et al. 2013; Cherney et al. 2016). Industrial hemp is a crop grown for fiber, seed, and cannabinoids. Uses in modern cultivation include biocomposite plastics, building material, seed oil, biofuel production, and cannabinoid extracts (Figure 1). More information on the hemp plant, its history, and modern cultivation is included in the EDIS publication Industrial Hemp in the United States: Definition and History (https://edis.ifas.ufl.edu/entity/topic/hemp\%20101\%20 series). In this follow-up publication, we discuss three main harvestable products of hemp: fiber, seeds, and cannabinoids, along with their current and potential uses.

\section{Fiber}

Hemp is a source of natural fiber that has been used in textiles and fabrics since the early Middle Ages. Ropes, sails, and fine clothing found at archaeological sites in Scandinavia were made of both hemp and flax fiber. Its fiber is more durable than cotton or synthetic fibers, making it resilient and long-lasting in clothing. The first pair of jeans designed by Levi Strauss was fabricated from hempen cloth. Hemp fiber can be combined with compatible alternate fabrics and prepared in several different ways. For instance, hemp wool is made by joining fibers with binding agents. It can be lighter in weight and have good insulating properties compared to synthetic fibers. Chemical treatments could also make this material more versatile with waterproof and windproof properties.



Figure 1. Hemp grown on commercial scale for CBD production. St. Lucie County, FL.

Credits: Christian Christensen, UF/IFAS

1. This document is SS-AGR-458, one of a series of the Agronomy Department, UF/IFAS Extension. Original publication date September 2021. Visit the EDIS website at https://edis.ifas.ufl.edu for the currently supported version of this publication.

2. Navdeep Kaur, M.S. student, Department of Soil and Water Sciences; Lakesh K. Sharma, assistant professor, soil fertility and sustainable agriculture, Department of Soil and Water Sciences; Christine Kelly-Begazo, county Extension director and Extension agent III, M.S., UF/IFAS Extension Indian River County; Mark Tancig, commercial/residential horticulture Extension agent, UF/IFAS Extension Leon County; and Zachary Brym, assistant professor, agroecology, Agronomy Department, UF/IFAS Tropical Research and Education Center; UF/IFAS Extension, Gainesville, FL 32611.

The Institute of Food and Agricultural Sciences (IFAS) is an Equal Opportunity Institution authorized to provide research, educational information and other services

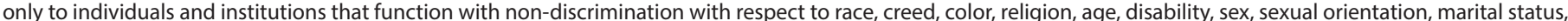
national origin, political opinions or affiliations. For more information on obtaining other UF/IFAS Extension publications, contact your county's UF/IFAS Extension office. U.S. Department of Agriculture, UF/IFAS Extension Service, University of Florida, IFAS, Florida A \& M University Cooperative Extension Program, and Boards of County Commissioners Cooperating. Nick T. Place, dean for UF/IFAS Extension. 
Some varieties of hemp have stems that consist of quality fibers made up of long phloem cells and woody core made up of xylem vessels (Figure 2). The higher-quality bast fibers are from the inner bark and have been described as long (2-25 mm), strong, lustrous, and very durable. Bast is considered a softer fiber (from stems), like jute (Corchorus spp.) and flax (Linum usitatissimum L.), rather than a hard fiber (from leaves), such as sisal (Agave sisalina L.) or abaca (Musa textilis L.). Bast fiber is hollow inside; it is also lightweight and demonstrates good mechanical strength. Bast fibers can be used for specialty paper, fabric, insulation, carpeting, and cordage (Gonzalez-Garcia et al. 2010). The inner core, or pith, is made up of short, woody fibers and is known as hurd. Hurd is also very low density and demonstrates desirable flexibility and strength. Hurd has a high water absorption capacity, almost five times its weight, and fibers are used for fiberboard, compost, paper filler, and absorbent animal bedding, and as a source of chemical components of plastics, paints, and sealants. Hurd used for animal bedding may reduce the incidence of allergic reactions occurring with straw.

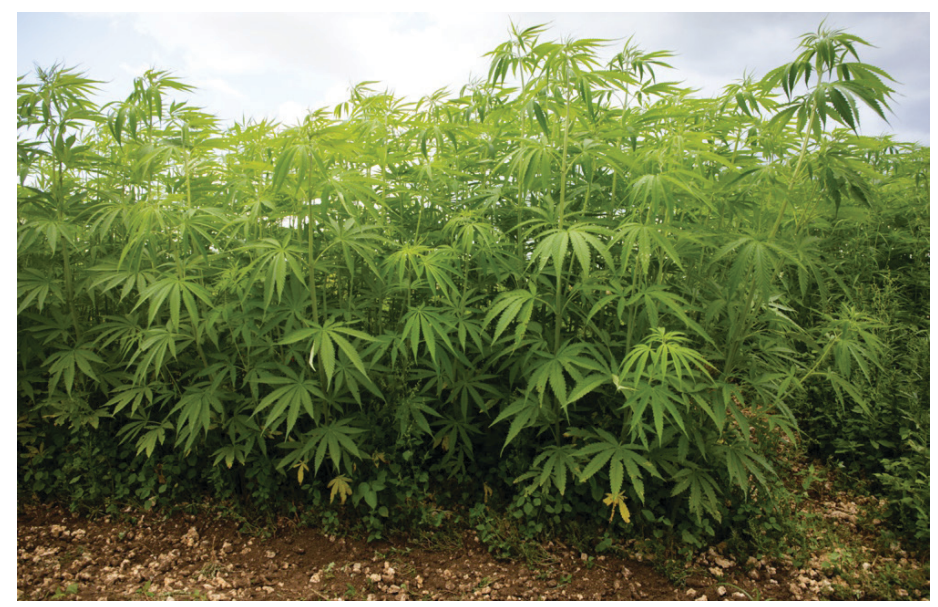

Figure 2. Fiber hemp grown at high density for slender stems. MiamiDade County, FL.

Credits: Tyler Jones, UF/IFAS

Hemp fiber can also be used for the pulp industry. Generally, current industrial pulp is extracted from trees (e.g., pine, eucalyptus, spruce) to make paper and cardboard. High demand for pulp has reduced the amount of forest acreage, especially in developing countries, and can severely limit this natural resource. Using hemp as a non-wood pulp can be an alternative for making paper and cardboard. Paper made from hemp is prepared by using a mixture of bast and hurd fibers. In Europe, 90\% of the paper prepared from hemp is used as cigarette paper. Other paper uses include banknotes, books, tea bags, and laboratory filter papers (Carus et al. 2013).
Hemp-containing composites and industrial applications are diverse. Composite materials made from hemp fiber can replace synthetic fiber composites, reducing the dependency on plastics and artificial fibers. Hemp fibers in composite materials may provide greater mechanical strength, durability, flexibility, heat resistance, and corrosion resistance compared to composites with synthetic fiber (Khoathane et al. 2016). Hemp fibers may also be more environmentally friendly and cheaper, replacing up to $30 \%$ of plastic in composite materials. Hemp can be used for building materials such as hempcrete. Cement and mortar made with hemp bast fiber and hurd have better insulating and noise absorption properties due to greater porosity of the material. Air trapped in between the hurd provides heat insulation, making buildings made with hemp cooler. Industrial hemp biomass, the combined harvest of stems and leaves, is also useful as a biofuel crop and has comparable yields as other lignocellulosic, nonfood crops used to produce biofuels like sorghum (Sorghum bicolor L.) and switchgrass (Panicum virgatum L.).

\section{Seeds}

Hemp seeds are botanically a fruit called an achene, and are notable for their high-quality oil; therefore, they are considered an oilseed rather than a grain (Figure 3). Oil extracted from hemp seeds is different from cannabinoid extracts. The use of hempseed as a grain-like food dates back thousands of years and is present in traditional Asian foods today. Hemp seeds for human consumption may continue to be an important part of the modern hemp market.

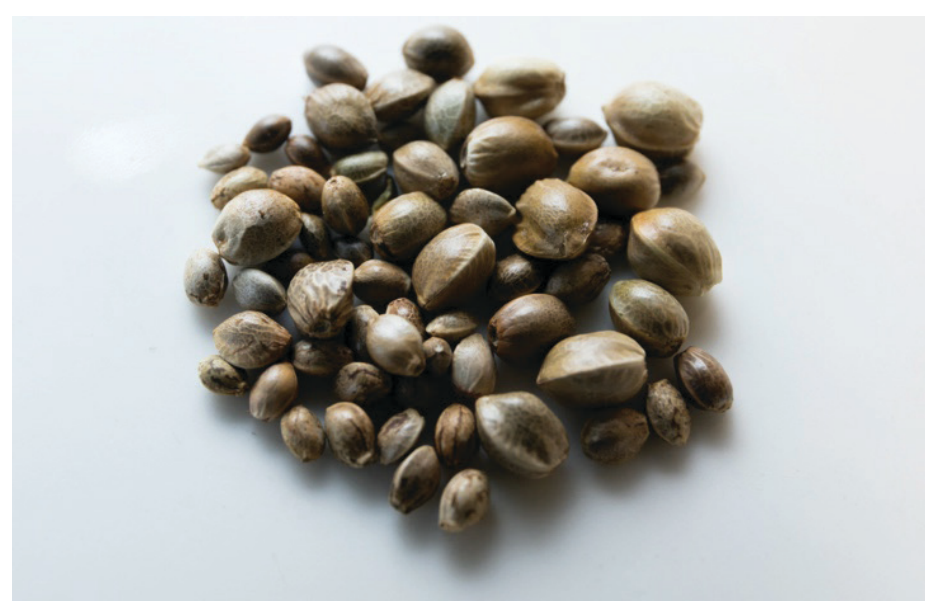

Figure 3. Diversity of hemp seeds across multiple crop types. The largest are selected varieties for seed harvest.

Credits: Tyler Jones, UF/IFAS

Hemp seeds can be used as whole seeds, dehulled seeds, and a source of oil. In Europe, $72.3 \%$ of the seeds produced are used as whole seed mostly for animal feed, $15.7 \%$ is used for oil extraction and for culinary purposes, and $11.7 \%$ of the seeds are dehulled for direct consumption. Hulled 
hemp seeds are nutty in flavor and are often called hemp nuts. Hemp seeds can also be ground into flour and further processed to collect protein, fat, or other constituents. Hemp flour has more fiber content and balanced protein than wheat and corn flour.

Hemp seeds contain all the nine essential amino acids required by humans (Callaway 2004; Leonard et al. 2019). Hemp seeds are a source of proteins, omega- 6 and omega- 3 fatty acids, antioxidants, and essential minerals such as potassium, sodium, magnesium, calcium, iron, phosphorus, and zinc (Leizer et al. 2000). The seeds generally contain $27 \%$ protein, $28 \%$ fats, and $37 \%$ fiber; however, these values also vary by hemp variety. The amino acid profile includes high amounts of arginine and glutamine but low amounts of lysine. Oil can be extracted from hemp seeds by cold compression and solvent extraction methods. This oil is known to contain $90 \%$ unsaturated fatty acids, such as oleic acid, alpha-linolenic acid, and linoleic acid (Devi and Khanam 2019). No other plant-extracted oil contains more than $90 \%$ unsaturated fatty acids.

Hemp seeds are also used in fish and bird feed. Additionally, hemp seed oil is used in cosmetic products such as lipsticks, lip balms, and soaps. The high concentration of polyunsaturated acids contained in the oil can be used for various industrial applications, including varnishes and paint drying agents.

\section{Cannabinoids}

Medicinal and therapeutic usage of Cannabis has motivated the development of hemp cultivation for cannabinoids (Amar 2006). Formal use of Cannabis as a drug dates back to 1854 when it was registered under the American pharmacopoeia. Cannabis was easily available from dispensaries until 1941 when it was removed from American pharmacopoeia. Use of Cannabis for medicine is primarily attributed to its more than 100 cannabinoids. The cannabinoid delta-9-tetrahydrocannabinol (THC) distinguishes hemp from marijuana, with hemp having a level of THC that does not exceed $0.3 \%$ per dry weight. The THC content in marijuana is more than $0.3 \%$ on dry weight basis.

The cultivation of hemp for cannabinoids has instead focused on cannabidiol (CBD) and cannabigerol (CBG). CBD and CBG lack the psychoactive properties of THC and have recognized therapeutic and medicinal benefits (VanDolah et al. 2019). Epidiolex was the first medicine prepared from CBD approved by the US Food and Drug Administration for the treatment of epilepsy. In the US, research is being carried out for the potential use of $\mathrm{CBD}$ for the treatment of 26 additional diseases including multiple sclerosis, anorexia, Parkinson's disease, glaucoma, asthma, inflammatory syndromes, heart disease, and cancer (Pisanti et al. 2017). Benefits and negative effects from CBD and other hemp products are still to be determined and may vary across commercially available products (Hazekamp 2018).

Most of the cannabinoids found in hemp are present in the secretory cells in the glandular trichomes on flowers and nearby leaves, collectively called inflorescence (Figure 4). Cannabinoid development is preferred for production in trichomes on unpollinated female flowers where cannabinoid concentration is highest. Cannabinoid concentration is lower in pollinated female flowers, leaves, and stems. During crop planting, only feminized seeds are used to prevent pollination by males and to obtain higher CBD production.

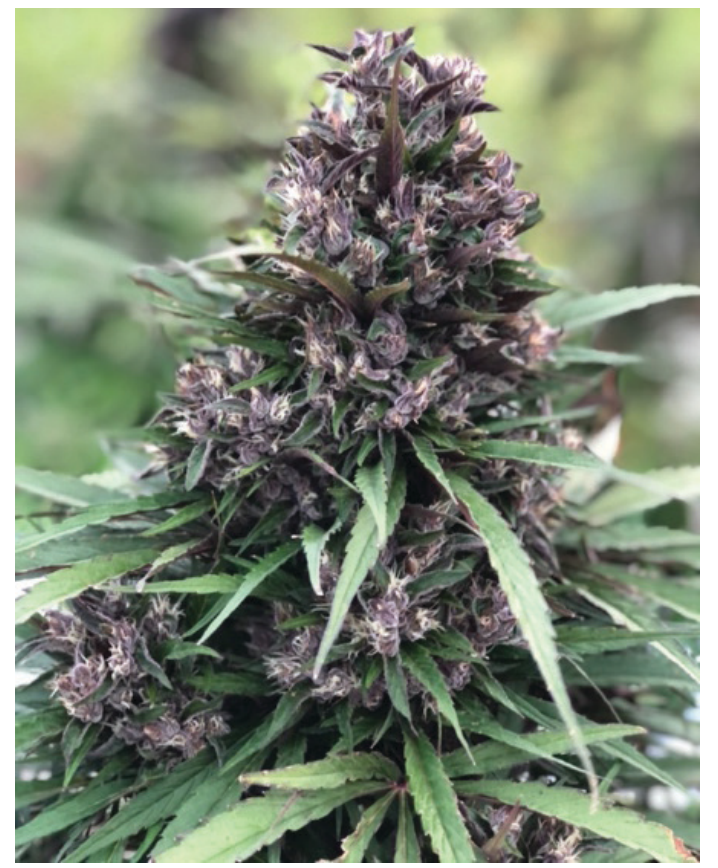

Figure 4. Hemp flowers high in cannabidiol. Indian River County. Credits: Carlos Hayden, Florida Hybrid Solutions, LLC

Cannabinoid extract is commonly marketed as an oil and component of several products. Oils of cannabinoids should not be confused with oil from hemp seed. Cannabinoid oils can be processed via several extraction methods with solvents such as carbon dioxide and ethanol. The cannabinoid extract is further processed, often isolating $\mathrm{CBD}$, then prepared in carrier oils and other products. Some hemp extracts can include THC at levels below the legal limit of $0.3 \%$ on dry weight basis. Hemp products should be labeled appropriately with explicit, third-party chemical analysis to declare cannabinoid content, as well as other additives or adulterants. 


\section{Conclusion}

Industrial hemp is an emerging crop, and the products obtained from it, such as fiber, seeds, and cannabinoids, have numerous uses. Hemp bast fibers are long, strong, durable, and suitable for use in the textile industry. Hemp hurd fibers are short but strong, flexible, and low-density; they are used in fiberboard, compost, and animal bedding. These fibers are also used for making paper and composites. Hemp seeds have high nutritional value as a source of proteins, unsaturated fatty acids, antioxidants, and essential minerals. They can be consumed whole, dehulled, or as a source of oil. Hemp cannabinoids are recognized for their therapeutic and medical uses. Given the diversity of hemp crops and their use, it is critical for hemp production to match the intended harvestable product and related market.

\section{References}

Amar, M. B. 2006. "Cannabinoids in Medicine: A Review of Their Therapeutic Potential." Journal of Ethnopharmacology 105(1-2): 1-25. https://doi.org/10.1016/j.jep.2006.02.001

Bouloc, P., S. Allegret, L. Arnaud, and G. Cousquer. 2013. Hemp: Industrial Production and Uses. Wallingford, Oxfordshrine: CABI Publishing.

Callaway, J. C. 2004. "Hempseed as a Nutritional Resource: An Overview." Euphytica 140:65-72. https://link.springer. com/content/pdf/10.1007/s10681-004-4811-6.pdf

Carus, M., S. Karst, A. Kauffmann, J. Hobson, and S. Bertucelli. 2013. The European Hemp Industry: Cultivation, Processing and Applications for Fibres, Shivs and Seeds.

Brussels, Belgium.

Cherney, J., and E. Small. 2016. "Industrial Hemp in North America: Production, Politics and Potential." Agronomy 6(4): 58. https://doi.org/10.3390/agronomy6040058

Devi, V., and S. Khanam. 2019. "Comparative Study of Different Extraction Processes for Hemp (Cannabis sativa) Seed Oil Considering Physical, Chemical and IndustrialScale Economic Aspects." Journal of Cleaner Production 207:645-57. https://doi.org/10.1016/j.jclepro.2018.10.036

González-García, S., A. Hospido, G. Feijoo, and M. T. Moreira. 2010. "Life Cycle Assessment of Raw Materials for Non-Wood Pulp Mills: Hemp and Flax." Resources, Conservation and Recycling 54(11): 923-30. https://doi. org/10.1016/j.resconrec.2010.01.011
Hazekamp, A. 2018. “The Trouble with CBD Oil.” Medical Cannabis and Cannabinoids 1(1): 65-72. https://doi. org/10.1159/000489287

Khoathane, M. C., O. C. Vorster, and E. R. Sadiku. 2008. "Hemp Fiber-Reinforced 1-Pentene/Polypropylene Copolymer: The Effect of Fiber Loading on the Mechanical and Thermal Characteristics of the Composites." Journal of Reinforced Plastics and Composites 27(14): 1533-44. https:// doi.org/10.1177/0731684407086325

Leizer, C., D. Ribnicky, A. Poulev, S. Dushenkov, and I. Raskin. 2000. "The Composition of Hemp Seed Oil and Its Potential as an Important Source of Nutrition." Journal of Nutraceuticals, Functional \& Medical Foods 2(4): 35-53. https://doi.org/10.1300/J133v02n04_04

Leonard, W., P. Zhang, D. Ying, and Z. Fang. 2019. "Hempseed in Food Industry: Nutritional Value, Health Benefits, and Industrial Applications." Comprehensive Reviews in Food Science and Food Safety 19(1): 282-308. https://doi. org/10.1111/1541-4337.12517

Pisanti, S., A. M. Malfitano, E. Ciaglia, A. Lamberti, R. Ranieri, G. Cuomo, M. Abate, et al. 2017. "Cannabidiol: State of the Art and New Challenges for Therapeutic Applications." Pharmacology and Therapeutics. Pergamon. https://doi.org/10.1016/j.pharmthera.2017.02.041

Vandolah, H. J., B. A. Bauer, and K. F. Mauck. 2019. "Clinicians' Guide to Cannabidiol and Hemp Oils." Mayo Clinic Proceedings 94(9): 1840-51. https://doi.org/10.1016/j. mayocp.2019.01.003 